\title{
Using Gamma-Ray to Determine the Homogeneity of Some Building Materials
}

\author{
Laith A. Najam ${ }^{1, *}$, Ahmed K. Mheemeed², Isra'a M. Hassan ${ }^{1}$ \\ ${ }^{1}$ Department of Physics, College of Science, University of Mosul, Iraq \\ ${ }^{2}$ Department of Physics, College of Education, University of Mosul, Iraq \\ *Corresponding author: dr_laithahmed@yahoo.com
}

Received February 11, 2014; Revised March 07, 2014; Accepted March 11, 2014

\begin{abstract}
In this paper, we use a narrow collimated beam of mono- energetic gamma rays emitted from the radioactive source ${ }^{137} \mathrm{Cs}(662 \mathrm{keV})$ and the system of measuring gamma rays UCS-20 associated with the sodium iodide detector $\mathrm{NaI}(\mathrm{Tl})$ to determine the homogeneity of the building materials, Granite, Marble, Cement, Ceramic and Bricks. The homogeneity test was determined from the percentage difference between the transmitted intensity of gamma-rays and the linear attenuation coefficient at different positions for each sample of the material then the percentage of standard deviation was checked.
\end{abstract}

Keywords: gamma-ray, homogeneity, building materials, sodium iodide detector NaI (Tl)

Cite This Article: Laith A. Najam, Ahmed K. Mheemeed, and Isra’a M. Hassan, "Using Gamma-Ray to Determine the Homogeneity of Some Building Materials.” International Journal of Physics, vol. 2, no. 1 (2014): 23-29. doi: 10.12691/ijp-2-1-5.

\section{Introduction}

Nuclear radiation is used in many fields including nuclear physics, medical physics, physics, health, agriculture, industry and other. These rays are used in industry for measuring the rate of flow of gases and liquids in pipelines and to study the friction between the surfaces, determine the amount of corrosion in the spare machines and, motors, control of the thickness of the plates made of metal and plastic, measure the density of liquids and pastes, and checking the homogeneity of materials and others. The homogeneity of thin films, plastics and rubbers can be studied through the variation in the energy, intensity and attenuation coefficient of nuclear radiation by using definite charge particles such as electrons, protons and alpha particles [1]. Beta particles emitted from the radioactive source ${ }^{90} \mathrm{Sr}[2,3]$ were used for measuring the homogeneity of mix rubber type MCG used in masks prevention. Electromagnetic radiations, $\mathrm{X}$ ray and $\gamma$-ray can be used in determining the degree of homogeneity of aluminum, iron, lead, alloys and other substances with high density. Technology use transmission gamma rays (GRT) and X-ray micro tomography ( $\mu$-CT) [4] to detect the presence of pores inside the material and determine the degree of homogeneity of the material. Gamma-rays emitted from radioactive sources ${ }^{137} \mathrm{Cs}$, ${ }^{152} \mathrm{Eu}$ and ${ }^{241} \mathrm{Am}$ are used for measuring the homogeneity of set of samples produced by mixing lead with a rubber type NBR with different weight ratios[5]. The homogeneity of these samples was studied through the variation in the transmitted intensity of gamma-rays and their linear attenuation coefficient.
As the usage of $\gamma$-ray increased in various fields from medical applications to food industry, it became important to get protection from their detrimental effects. There are three general rules of protections: time, distance and shielding. In most cases, shielding is the main rule to be performed [6]. The attenuation coefficient is important parameter for studying interaction of $\gamma$-ray with matter that gives us the fraction of energy scattered or absorbed. The attenuation coefficient can be extensively found in the literature. Many authors have studied $\gamma$-ray attenuation coefficient in shielding materials $[5,7,8,9,10]$.

The building materials used in our markets are different in their homogeneity, so we used gamma rays emitted from the radioactive source ${ }^{137} \mathrm{Cs}$ and the system of measuring gamma rays UCS-20 associated with the sodium iodide detector $\mathrm{NaI}(\mathrm{Tl})$ in the examination of the homogeneity of building materials used in Nineveh governorate (Iraq). The linear attenuation coefficients for the building materials were determined

\section{Experimental Method}

In the present study, 16 samples of building materials were collected from the local markets at Nineveh governorate, some are produced inside the country and others are imported. These materials are Granite, Marble, Cement, Ceramic and Bricks. The homogeneity test of these materials were determined by studying the variations in the transmitted intensity of gamma-rays at four positions for each sample of the studied materials, linear attenuation coefficient and the percentage of standard deviation. The homogeneity test was performed by using the gamma ray system UCS-20 associated with the 
sodium iodide detector $\mathrm{NaI}(\mathrm{Tl})$ with dimensions $2.5 \mathrm{~cm} \times$ $3.8 \mathrm{~cm}$ shown in Figure 1. This system consists of preamplifier, amplifier, power supply, multi channel analyzer and a personal computer for the purpose of operating, reading measurements and analysis of the results. A narrow collimated beam of mono- energetic gamma rays emitted from the radioactive source ${ }^{137} \mathrm{Cs}$ (662 keV) was obtained using a lead Cylinder with height $(70 \mathrm{~mm})$, diameter $(60 \mathrm{~mm})$ and an internal hole with diameter $(4 \mathrm{~mm})$. The sample was placed inside a slot with width equal to the sample thickness $(10 \mathrm{~mm}, 20 \mathrm{~mm})$ as shown in Figure 1.

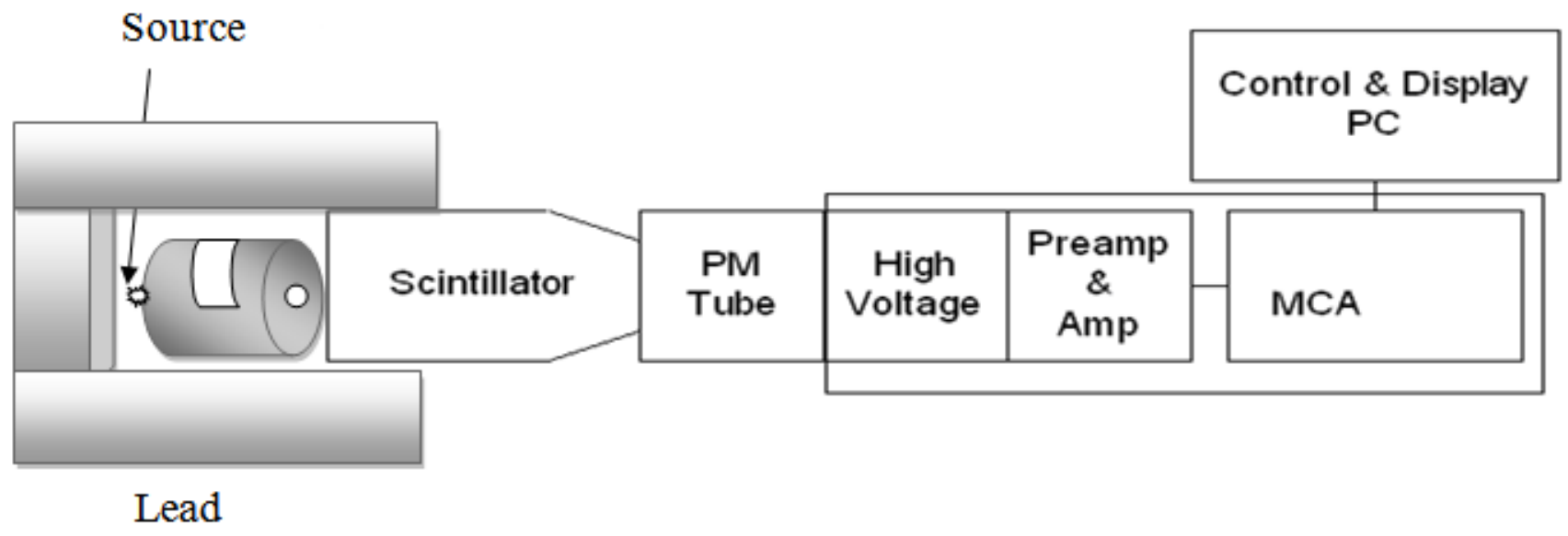

Figure 1. Experimental arrangement

\section{Calculations}

\subsection{Variation of Intensity}

When the narrow beam of mono- energetic gamma rays is incident with intensity $I_{0}$ at a material medium, the intensity of transmitted rays I is [1] :

$$
\mathrm{I}=\mathrm{I}_{\mathrm{o}} \mathrm{e}^{-\mu x}
$$

Where: $\mu$ is the linear attenuation coefficient which depends on the energy of gamma rays and the components of the material medium.

The homogeneity of the material can be known by comparing the intensity of transmitted gamma radiation I through identified sites in the material with average values of I' for all positions. Besides we can determine the percentage of the homogeneity of material $\Delta_{\mathrm{I}}(\%)$ by using the following relationship:

$$
\Delta_{\mathrm{I}}(\%)=\frac{\mathrm{I}^{\prime}-\mathrm{I}}{\mathrm{I}^{\prime}} \times 100 \%
$$

\subsection{Variation of Linear Attenuation Coefficient}

The linear attenuation Coefficient of gamma rays $\mu$ has been calculated by using equation (1). The homogeneity of the material can be worked out by comparing the values of $\mu$ in the specific locations in the material with the average values of $\mu^{\prime}$. The percentage of the homogeneity of material $\Delta_{\mu}(\%)$ is given by:

$$
\Delta_{\mu}(\%)=\frac{\mu^{\prime}-\mu}{\mu^{\prime}} \times 100 \%
$$

\subsection{Percentage of Standard Deviation}

The values of the standard deviations were calculated using the following formulae.

$$
\begin{gathered}
\sigma_{\mu}=\left[\sum\left(\mu_{i}-\mu^{\prime}\right)^{2} /(N-1)\right]^{0.5} \\
\sigma_{I}=\left[\sum\left(I_{i}-I\right)^{2} /(N-1)\right]^{0.5}
\end{gathered}
$$

Where:

$\sigma$ is the standard deviation

$\mathrm{N}=4$ is the number of measured positions of each sample.

$$
\begin{aligned}
& \text { The percentage of standard deviation } \\
& =((\sigma / \text { Ave }) \times 100)
\end{aligned}
$$

Whenever the values of $\Delta_{\mathrm{I}}(\%), \Delta_{\mu}(\%)$ and $((\sigma /$ Ave $) \times$ 100) do increase, it means that the homogeneity of materials does increase [5].

\section{Results and Discussion}

Table 1 to Table 5 contain the values of $\mathrm{I}_{\mathrm{O}}, \rho, \mathrm{x}, \mathrm{p}, \mathrm{I}, \mu$, $\Delta_{\mathrm{I}}(\%)$ and $\Delta_{\mu}(\%)$ at four positions for each sample of the studied materials, Granite, Marble, Cement, Ceramic and Bricks. The values of I', $\mu^{\prime}, \sigma$ and the percentage values of standard deviation $((\sigma /$ Ave $) \times 100)$ are also illustrated in these tables. The relationship between each of $\Delta_{\mathrm{I}}(\%)$ and $\Delta_{\mu}(\%)$ at four positions of the studied materials are shown in Figure 2 to Figure 6. We note from these tables and figures that the positive values of $\Delta_{\mathrm{I}}(\%)$ corresponde to negative values of $\Delta_{\mu}(\%)$, which means that any decrease in $\mu$ offset is caused by an increase in I at any position and vice versa. It is clear from Table 1 and Figure 2 that the minimum and maximum values of $\Delta_{\mathrm{I}}(\%)$ and $\Delta_{\mu}(\%)$ have been obtained in Turkish and Chinese Granite, respectively. The lower and higher percentage values of standard deviation $\left(\left(\sigma_{I} / I^{\prime}\right) \times 100\right)$ and $\left(\left(\sigma_{\mu} / \mu^{\prime}\right) \times 100\right)$ were $1.61 \%, 4.01 \%$ and $4.04 \%, 9.28 \%$ and found in Turkish and Chinese Granite, respectively. The Turkish Granite is more homogeneous than the Chinese Granite. 
Figure 3 and Table 2 show that the lowest and highest values of $\Delta_{\mathrm{I}}(\%)$ and $\Delta_{\mu}(\%)$ were detected in Turkish and Spanish Marble, respectively. The lower and higher percentage values of standard deviation $\left(\left(\sigma_{\ddagger} / \mathrm{I}^{\prime}\right) \times 100\right)$ and $\left(\left(\sigma_{\mu} / \mu^{\prime}\right) \times 100\right)$ were $1.283 \%, 3.55 \%$ and $1.61 \%$, $4.84 \%$ and found in Turkish and Spanish Marbles. The Turkish Marble is more homogeneous than the Spanish Marble. The highest and lowest values of $\Delta_{\mathrm{I}}(\%)$ and $\Delta_{\mu}(\%)$ were found in Iraqi and Turkish Cement, respectively and shown in Table 3 and Figure 4 . The higher and lower percentage values of standard deviation $\left(\left(\sigma_{t} / \mathrm{I}^{\prime}\right) \times 100\right)$ and $\left(\left(\sigma_{\mu} / \mu^{\prime}\right) \times 100\right)$ were $1.73 \%, 5.0 \%$ and $1.57 \%$, $4.35 \%$ and found in Iraqi and Turkish Cement, respectively. The Turkish Cement is more homogeneous than the Iraqi Cement. It is clear from Table 4 and Figure 5 that the minimum and maximum values of $\Delta_{\mathrm{I}}(\%)$ and $\Delta_{\mu}(\%)$ have been obtained in Spanish and Italian Ceramic, respectively. The lower and higher percentage values of standard deviation $\left(\left(\sigma_{I} / I^{\prime}\right) \times 100\right)$ and $\left(\left(\sigma_{\mu} / \mu^{\prime}\right) \times 100\right)$ were $0.539 \%, 3.47 \%$ and $0.556 \%, 3.8 \%$ and found in Spanish and Italian Ceramic, respectively. The Spanish Ceramic is more homogeneous than the Italian Ceramic. We found from Figure 6 and Table 5 that the lowest and highest values of $\Delta_{\mathrm{I}}(\%)$ and $\Delta_{\mu}(\%)$ were detected in Iranian and Iraqi Bricks, respectively. The lower and higher percentage values of standard deviation $\left(\left(\sigma_{ \pm} / \mathrm{I}^{\prime}\right) \times\right.$ $100)$ and $\left(\left(\sigma_{\mu} / \mu^{\prime}\right) \times 100\right)$ were $0.733 \%, 2.06 \%$ and $0.938 \%, 3.12 \%$ and found in Iranian and Iraqi Bricks. The Iranian Brick is more homogeneous than the Iraqi Brick. Current results show that the Spanish Ceramic sample is more homogeneous while the Chinese Granite sample is less homogeneous as compared with the other building materials.
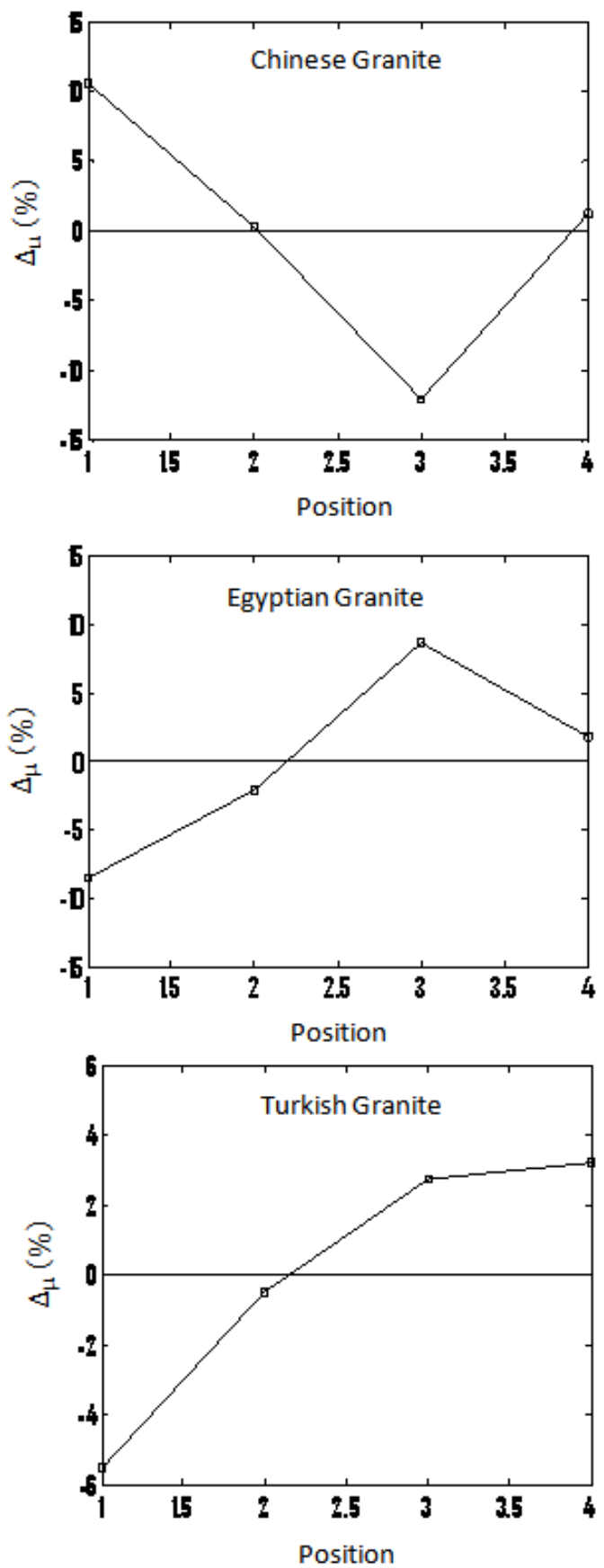

Figure 2. The relationship between each $\Delta_{\mathrm{I}}(\%)$ and $\Delta_{\mu}(\%)$ with the position for Granite material 
Table 1. The results of homogeneity tests of Granite material Iraqi Granite

\begin{tabular}{|c|c|c|c|c|}
\hline \multicolumn{5}{|c|}{ Iraqi Granite } \\
\hline \multicolumn{5}{|c|}{$\mathrm{I}_{\mathrm{O}}($ count $/ 1800 \mathrm{sec})=6457, \rho=2.69 \mathrm{~g} / \mathrm{cm}^{3}, \mathrm{x}=2.064 \mathrm{~cm}$} \\
\hline $\mathrm{p}$ & I(count/1800sec) & $\Delta_{\mathrm{I}}(\%)$ & $\mu\left(\mathrm{cm}^{-1}\right)$ & $\Delta_{\mu}(\%)$ \\
\hline 1 & 4130 & 1.97 & 0.216 & -4.60 \\
\hline 2 & 4096 & 2.78 & 0.220 & -6.53 \\
\hline 3 & 4359 & -3.45 & 0.190 & 7.99 \\
\hline 4 & 4268 & -1.29 & 0.200 & -3.14 \\
\hline Ave & 4213 & 0 & 0.206 & 0 \\
\hline$\sigma$ & 122.36 & & 0.0139 & \\
\hline$(\sigma /$ Ave $) \times 100$ & 2.90 & & 6.74 & \\
\hline \multicolumn{5}{|c|}{ Spanish Granite } \\
\hline \multicolumn{5}{|c|}{$\mathrm{I}_{\mathrm{O}}($ count $/ 1800 \mathrm{sec})=6459, \rho=2.66 \mathrm{~g} / \mathrm{cm}^{3}, \mathrm{x}=2.035 \mathrm{~cm}$} \\
\hline $\mathrm{p}$ & I(count/1800sec) & $\Delta_{\mathrm{I}}(\%)$ & $\mu\left(\mathrm{cm}^{-1}\right)$ & $\Delta_{\mu}(\%)$ \\
\hline 1 & 4250 & -0.884 & 0.205 & 2.14 \\
\hline 2 & 4336 & -2.92 & 0.195 & 6.92 \\
\hline 3 & 4196 & 0.397 & 0.211 & -0.715 \\
\hline 4 & 4069 & 3.41 & 0.227 & -8.35 \\
\hline Ave & 4212 & 0 & 0.209 & 0 \\
\hline$\sigma$ & 111.8 & & 0.0134 & \\
\hline$(\sigma /$ Ave $) \times 100$ & 2.65 & & 6.41 & \\
\hline \multicolumn{5}{|c|}{ Indian Granite } \\
\hline \multicolumn{5}{|c|}{$\mathrm{I}_{\mathrm{O}}($ count $/ 1800 \mathrm{sec})=6059, \rho=2.68 \mathrm{~g} / \mathrm{cm}^{3}, \mathrm{x}=1.747 \mathrm{~cm}$} \\
\hline $\mathrm{p}$ & I(count/1800sec) & $\Delta_{\mathrm{I}}(\%)$ & $\mu\left(\mathrm{cm}^{-1}\right)$ & $\Delta_{\mu}(\%)$ \\
\hline 1 & 4303 & -0.48 & 0.195 & 1.51 \\
\hline 2 & 4352 & -1.62 & 0.189 & 4.54 \\
\hline 3 & 4164 & 2.76 & 0.214 & -8.08 \\
\hline 4 & 4310 & -0.65 & 0.194 & 2.02 \\
\hline Ave & 4245 & 0 & 0.198 & 0 \\
\hline$\sigma$ & 81.74 & & 0.0109 & \\
\hline$(\sigma /$ Ave $) \times 100$ & 1.91 & & 5.55 & \\
\hline \multicolumn{5}{|c|}{ Chinese Granite } \\
\hline \multicolumn{5}{|c|}{$\mathrm{I}_{\mathrm{O}}($ count $/ 1800 \mathrm{sec})=6568, \mathrm{x}=2.145 \mathrm{~cm}, \rho=2.65 \mathrm{~g} / \mathrm{cm}^{3}$} \\
\hline $\mathrm{p}$ & I(count/1800sec) & $\Delta_{\mathrm{I}}(\%)$ & $\mu\left(\mathrm{cm}^{-1}\right)$ & $\Delta_{\mu}(\%)$ \\
\hline 1 & 4440 & -4.59 & 0.182 & 10.6 \\
\hline 2 & 4252 & -0.16 & 0.203 & 0.25 \\
\hline 3 & 4022 & 5.25 & 0.228 & -12.0 \\
\hline 4 & 4266 & -0.49 & 0.201 & 1.23 \\
\hline Ave & 4245 & 0 & 0.2035 & 0 \\
\hline$\sigma$ & 171.5 & & 0.0189 & \\
\hline$(\sigma /$ Ave $) \times 100$ & 4.04 & & 9.28 & \\
\hline \multicolumn{5}{|c|}{ Egyptian Granite } \\
\hline \multicolumn{5}{|c|}{$\mathrm{I}_{\mathrm{O}}($ count $/ 1800 \mathrm{sec})=6601, \rho=2.61 \mathrm{~g} / \mathrm{cm}^{3}, \mathrm{x}=1.754 \mathrm{~cm}$} \\
\hline $\mathrm{p}$ & I(count/1800sec) & $\Delta_{\mathrm{I}}(\%)$ & $\mu\left(\mathrm{cm}^{-1}\right)$ & $\Delta_{\mu}(\%)$ \\
\hline 1 & 4478 & 2.98 & 0.221 & -8.46 \\
\hline 2 & 4580 & 0.77 & 0.208 & -2.08 \\
\hline 3 & 4763 & -3.19 & 0.186 & 8.71 \\
\hline 4 & 4642 & -0.56 & 0.200 & 1.84 \\
\hline Ave & 4615 & 0 & 0.203 & 0 \\
\hline$\sigma$ & 119.2 & & 0.014 & \\
\hline$(\sigma /$ Ave $) \times 100$ & 2.58 & & 7.19 & \\
\hline \multicolumn{5}{|c|}{ Turkish Granite } \\
\hline \multicolumn{5}{|c|}{$\mathrm{I}_{\mathrm{O}}($ count $/ 1800 \mathrm{sec})=6556, \rho=2.69 \mathrm{~g} / \mathrm{cm}^{3}, \mathrm{x}=1.862 \mathrm{~cm}$} \\
\hline $\mathrm{p}$ & I(count/1800sec) & $\Delta_{\mathrm{I}}(\%)$ & $\mu\left(\mathrm{cm}^{-1}\right)$ & $\Delta_{\mu}(\%)$ \\
\hline 1 & 4272 & 2.20 & 0.230 & -5.50 \\
\hline 2 & 4360 & 0.190 & 0.219 & -0.45 \\
\hline 3 & 4417 & -1.11 & 0.212 & 2.75 \\
\hline 4 & 4425 & -1.29 & 0.211 & 3.21 \\
\hline Ave & 4368 & 0 & 0.218 & 0 \\
\hline$\sigma$ & 70.5 & & 0.00875 & \\
\hline$(\sigma /$ Ave $) \times 100$ & 1.61 & & 4.01 & \\
\hline
\end{tabular}

Table 2. The results of homogeneity tests of Marble material Turkish Marble

\begin{tabular}{|c|c|c|c|c|}
\hline \multicolumn{5}{|c|}{ Turkish Marble } \\
\hline \multicolumn{5}{|c|}{$\mathrm{I}_{\mathrm{O}}($ count $/ 1800 \mathrm{sec})=6580, \rho=2.53 \mathrm{~g} / \mathrm{cm} 3, \mathrm{x}=1.750 \mathrm{~cm}$} \\
\hline $\mathrm{p}$ & I(count/1800sec) & $\Delta_{\mathrm{I}}(\%)$ & $\mu\left(\mathrm{cm}^{-1}\right)$ & $\Delta_{\mu}(\%)$ \\
\hline 1 & 4622 & 0.91 & 0.201 & -2.55 \\
\hline 2 & 4680 & -0.32 & 0.194 & 1.02 \\
\hline 3 & 4614 & 1.08 & 0.202 & -3.06 \\
\hline 4 & 4743 & -1.67 & 0.187 & 4.59 \\
\hline Ave & 4664 & 0 & 0.196 & 0 \\
\hline$\sigma$ & 59.88 & & 0.00697 & \\
\hline$(\sigma /$ Ave $) \times 100$ & 1.283 & & 3.55 & \\
\hline \multicolumn{5}{|c|}{ Spanish Marble } \\
\hline \multicolumn{5}{|c|}{$\mathrm{I}_{\mathrm{O}}($ count $/ 1800 \mathrm{sec})=6414, \rho=2.55 \mathrm{~g} / \mathrm{cm}^{3}, \mathrm{x}=1.773 \mathrm{~cm}$} \\
\hline $\mathrm{p}$ & $\mathrm{I}($ count/1800sec) & $\Delta \mathrm{I}(\%)$ & $\mu\left(\mathrm{cm}^{-1}\right)$ & $\Delta \mu(\%)$ \\
\hline 1 & 4639 & -2.10 & 0.182 & 6.30 \\
\hline 2 & 4475 & 1.50 & 0.203 & -4.50 \\
\hline 3 & 4499 & 0.97 & 0.200 & -2.96 \\
\hline 4 & 4560 & -0.36 & 0.192 & 1.15 \\
\hline Ave & 4543 & 0 & 0.194 & 0 \\
\hline$\sigma$ & 73.17 & & 0.0093 & \\
\hline$(\sigma /$ Ave $) \times 100$ & 1.61 & & 4.84 & \\
\hline \multicolumn{5}{|c|}{ Indian Marble } \\
\hline \multicolumn{5}{|c|}{$\mathrm{I}_{\mathrm{O}}($ count $/ 1800 \mathrm{sec})=6568, \rho=2.60 \mathrm{~g} / \mathrm{cm}^{3}, \mathrm{x}=2.088 \mathrm{~cm}$} \\
\hline $\mathrm{p}$ & $\mathrm{I}$ (count/1800sec) & $\Delta \mathrm{I}(\%)$ & $\mu\left(\mathrm{cm}^{-1}\right)$ & $\Delta \mu(\%)$ \\
\hline 1 & 4303 & 1.52 & 0.203 & -4.10 \\
\hline 2 & 4347 & 0.51 & 0.197 & -1.03 \\
\hline 3 & 4469 & -2.27 & 0.184 & 5.64 \\
\hline 4 & 4359 & 0.24 & 0.195 & $0.51-$ \\
\hline Ave & 4369 & 0 & 0.196 & 0 \\
\hline$\sigma$ & 70.5 & & 0.0079 & \\
\hline$(\sigma /$ Ave $) \times 100$ & 1.61 & & 4.08 & \\
\hline \multicolumn{5}{|c|}{ Italian Marble } \\
\hline \multicolumn{5}{|c|}{$\mathrm{I}_{\mathrm{O}}($ count $/ 1800 \mathrm{sec})=6386, \mathrm{x}=2.076 \mathrm{~cm}, \rho=2.56 \mathrm{~g} / \mathrm{cm}^{3}$} \\
\hline $\mathrm{p}$ & I(count/1800sec) & $\Delta \mathrm{I}(\%)$ & $\mu\left(\mathrm{cm}^{-1}\right)$ & $\Delta \mu(\%)$ \\
\hline 1 & 4211 & 1.78 & 0.200 & -4.43 \\
\hline 2 & 4260 & 0.64 & 0.195 & -1.82 \\
\hline 3 & 4309 & -0.50 & 0.189 & 1.30 \\
\hline 4 & 4370 & -1.92 & 0.182 & 4.69 \\
\hline Ave & 4287 & 0 & 0.191 & 0 \\
\hline$\sigma$ & 68.0 & & 0.0077 & \\
\hline$(\sigma /$ Ave $) \times 100$ & 1.58 & & 4.05 & \\
\hline
\end{tabular}

Table 3. The results of homogeneity tests of Cement material Iraqi Cement

\begin{tabular}{|c|c|c|c|c|}
\hline \multicolumn{5}{|c|}{ Iraqi Cement } \\
\hline \multicolumn{5}{|c|}{$\mathrm{I}_{\mathrm{O}}$ (count $\left./ 1800 \mathrm{sec}\right)=6418, \rho=2.40 \mathrm{~g} / \mathrm{cm}^{3}, \mathrm{x}=1.859 \mathrm{~cm}$} \\
\hline $\mathrm{p}$ & $\mathrm{I}(\mathrm{count} / 1800 \mathrm{sec})$ & $\Delta_{\mathrm{I}}(\%)$ & $\mu\left(\mathrm{cm}^{-1}\right)$ & $\Delta_{\mu}(\%)$ \\
\hline 1 & 4617 & -2.03 & 0.177 & 5.85 \\
\hline 2 & 4425 & 2.20 & 0.200 & -6.38 \\
\hline 3 & 4524 & 0.016 & 0.188 & 0 \\
\hline 4 & 4533 & -0.18 & 0.187 & 0.53 \\
\hline Ave & 4524 & 0 & 0.188 & 0 \\
\hline$\sigma$ & 78.58 & & 0.0094 & \\
\hline$(\sigma /$ Ave $) \times 100$ & 1.73 & & 5.00 & \\
\hline \multicolumn{5}{|c|}{ Turkish Cement } \\
\hline \multicolumn{5}{|c|}{$\mathrm{I}_{\mathrm{O}}($ count $/ 1800 \mathrm{sec})=6597, \rho=2.42 \mathrm{~g} / \mathrm{cm}^{3}, \mathrm{x}=1.845 \mathrm{~cm}$} \\
\hline $\mathrm{p}$ & $\mathrm{I}($ count/1800sec) & $\Delta_{\mathrm{I}}(\%)$ & $\mu\left(\mathrm{cm}^{-1}\right)$ & $\Delta_{\mu}(\%)$ \\
\hline 1 & 4595 & 0.059 & 0.196 & -0.25 \\
\hline 2 & 4629 & -0.67 & 0.192 & 1.79 \\
\hline 3 & 4499 & 2.14 & 0.207 & -5.88 \\
\hline 4 & 4668 & -1.52 & 0.187 & 4.34 \\
\hline Ave & 4597 & 0 & 0.195 & 0 \\
\hline$\sigma$ & 72.27 & & 0.0085 & \\
\hline$(\sigma /$ Ave $) \times 100$ & 1.57 & & 4.35 & \\
\hline
\end{tabular}


Table 4. The results of homogeneity tests of Ceramic material Spanish Ceramic

\begin{tabular}{|c|c|c|c|c|}
\hline \multicolumn{5}{|c|}{ Spanish Ceramic } \\
\hline \multicolumn{5}{|c|}{$\mathrm{I}_{\mathrm{O}}($ count $/ 1800 \mathrm{sec})=5714, \rho=2.32 \mathrm{~g} / \mathrm{cm}^{3}, \mathrm{x}=0.925 \mathrm{~cm}$} \\
\hline $\mathrm{p}$ & $\mathrm{I}(\mathrm{count} / 1800 \mathrm{sec})$ & $\Delta_{\mathrm{I}}(\%)$ & $\mu\left(\mathrm{cm}^{-1}\right)$ & $\Delta_{\mu}(\%)$ \\
\hline 1 & 4877 & -0.169 & 0.171 & 0.869 \\
\hline 2 & 4831 & 0.775 & 0.181 & -4.92 \\
\hline 3 & 4875 & -0.128 & 0.171 & 0.869 \\
\hline 4 & 4892 & -0.477 & 0.167 & 3.18 \\
\hline Ave & 4868 & 0 & 0.172 & 0 \\
\hline$\sigma$ & 26.28 & & 0.00597 & \\
\hline$(\sigma /$ Ave $) \times 100$ & 0.539 & & 3.47 & \\
\hline \multicolumn{5}{|c|}{ Italian Ceramic } \\
\hline \multicolumn{5}{|c|}{$\mathrm{I}_{\mathrm{O}}($ count $/ 1800 \mathrm{sec})=5943, \rho=2.37 \mathrm{~g} / \mathrm{cm}^{3}, \mathrm{x}=0.914 \mathrm{~cm}$} \\
\hline $\mathrm{p}$ & $\mathrm{I}(\mathrm{count} / 1800 \mathrm{sec})$ & $\Delta_{\mathrm{I}}(\%)$ & $\mu\left(\mathrm{cm}^{-1}\right)$ & $\Delta_{\mu}(\%)$ \\
\hline 1 & 5097 & -0.15 & 0.168 & 0.88 \\
\hline 2 & 5068 & 0.41 & 0.175 & -3.24 \\
\hline 3 & 5126 & -0.72 & 0.161 & 5.01 \\
\hline 4 & 5066 & 0.45 & 0.174 & -2.65 \\
\hline Ave & 5089 & 0 & 0.169 & 0 \\
\hline$\sigma$ & 28.3 & & 0.0064 & \\
\hline$(\sigma /$ Ave $) \times 100$ & 0.556 & & 3.80 & \\
\hline
\end{tabular}
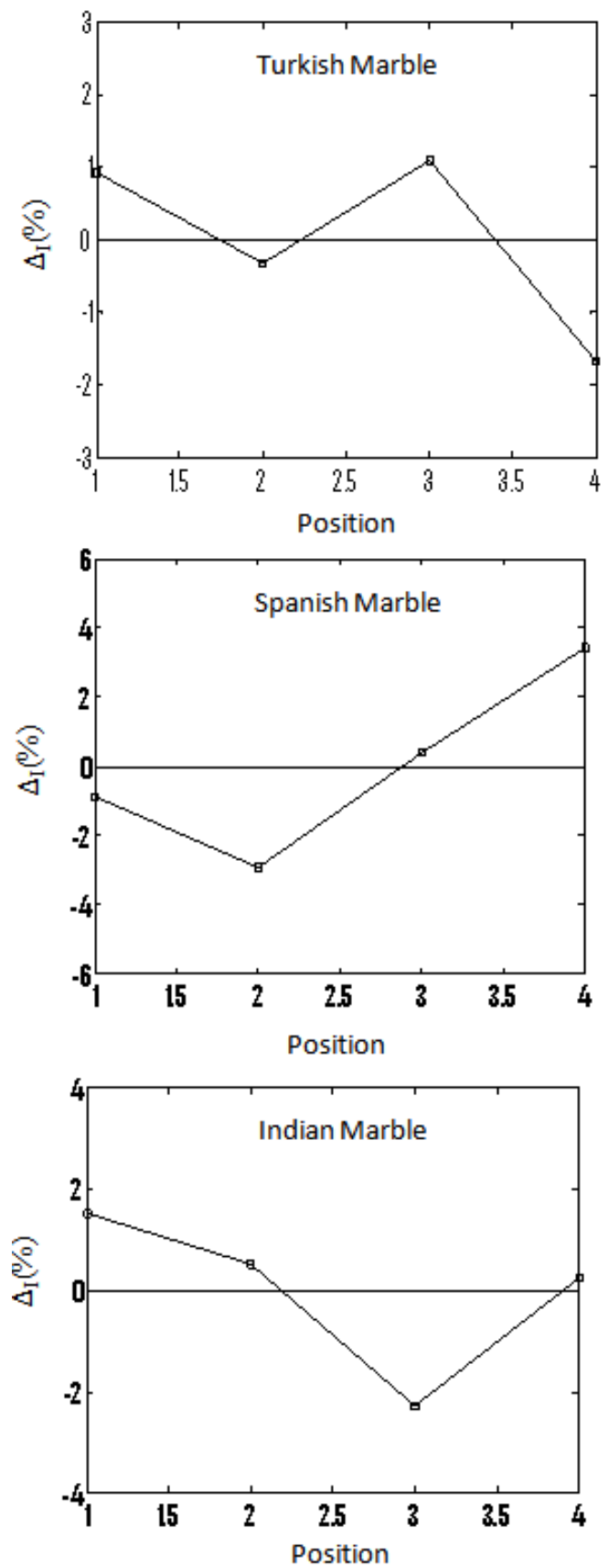

Table 5. The results of homogeneity tests of Brick material Iraqi Brick

\begin{tabular}{|c|c|c|c|c|}
\hline \multicolumn{5}{|c|}{ Iraqi Brick } \\
\hline \multicolumn{5}{|c|}{$\mathrm{I}_{\mathrm{O}}($ count $/ 1800 \mathrm{sec})=6587, \rho=1.97 \mathrm{~g} / \mathrm{cm}^{3}, \mathrm{x}=1.983 \mathrm{~cm}$} \\
\hline $\mathrm{p}$ & $\mathrm{I}$ (count/1800sec) & $\Delta_{\mathrm{I}}(\%)$ & $\mu\left(\mathrm{cm}^{-1}\right)$ & $\Delta_{\mu}(\%)$ \\
\hline 1 & 4802 & -0.010 & 0.159 & 0 \\
\hline 2 & 4767 & 0.71 & 0.163 & -2.51 \\
\hline 3 & 4772 & 0.61 & 0.162 & -1.88 \\
\hline 4 & 4865 & -1.32 & 0.152 & 4.40 \\
\hline Ave & 4801 & 0 & 0.159 & 0 \\
\hline$\sigma$ & 45.06 & & 0.0049 & \\
\hline$(\sigma /$ Ave $) \times 100$ & 0.938 & & 3.12 & \\
\hline \multicolumn{5}{|c|}{ Iranian Brick } \\
\hline \multicolumn{5}{|c|}{$\mathrm{I}_{\mathrm{O}}($ count $/ 1800 \mathrm{sec})=6680, \rho=1.93 \mathrm{~g} / \mathrm{cm}^{3}, \mathrm{x}=2.099 \mathrm{~cm}$} \\
\hline $\mathrm{p}$ & $\mathrm{I}(\mathrm{count} / 1800 \mathrm{sec})$ & $\Delta_{\mathrm{I}}(\%)$ & $\mu\left(\mathrm{cm}^{-1}\right)$ & $\Delta_{\mu}(\%)$ \\
\hline 1 & 4802 & -0.82 & 0.157 & 2.18 \\
\hline 2 & 4767 & -0.089 & 0.160 & 0.31 \\
\hline 3 & 4765 & -0.047 & 0.160 & 0.31 \\
\hline 4 & 4717 & 0.96 & 0.165 & -2.80 \\
\hline Ave & 4762 & 0 & 0.160 & 0 \\
\hline$\sigma$ & 34.9 & & 0.0033 & \\
\hline$(\sigma /$ Ave $) \times 100$ & 0.733 & & 2.06 & \\
\hline
\end{tabular}
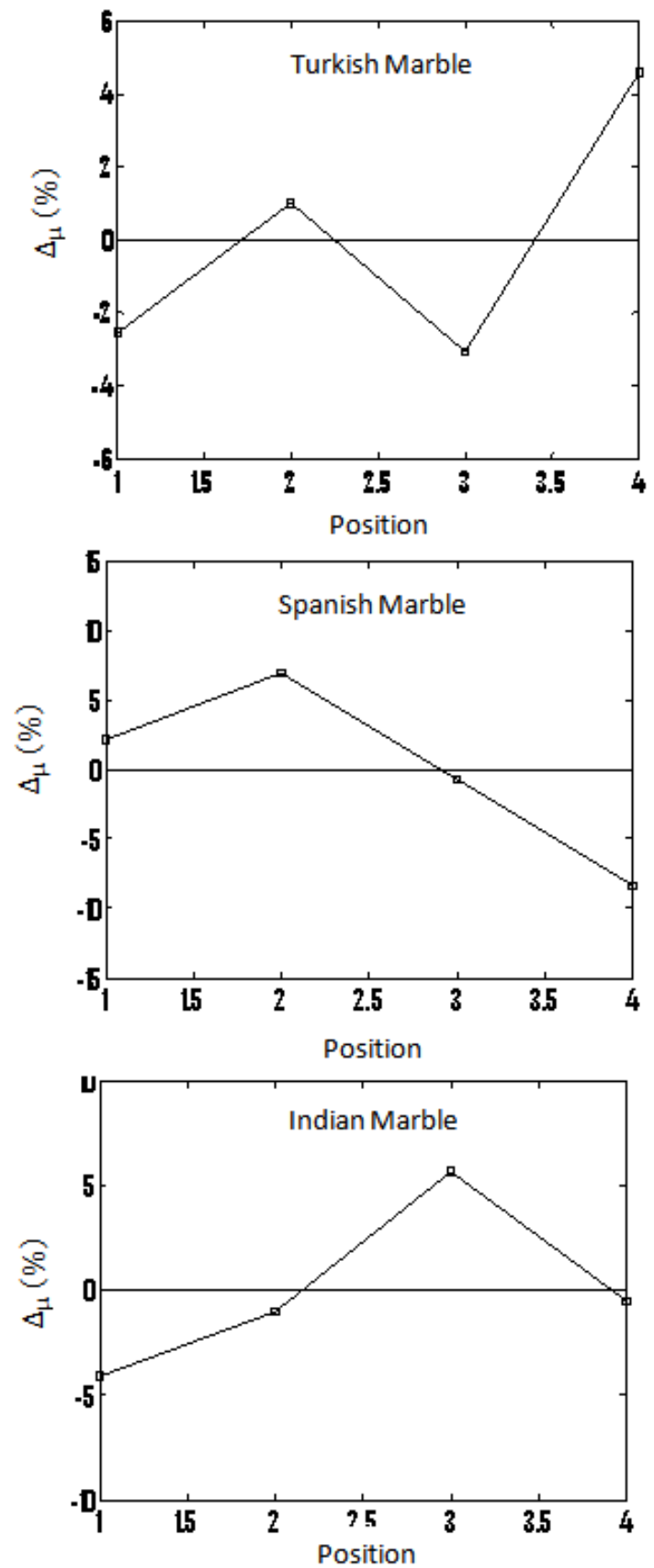

Figure 3. The relationship between each $\Delta_{\mathrm{I}}(\%)$ and $\Delta_{\mu}(\%)$ with the position for Marble material 

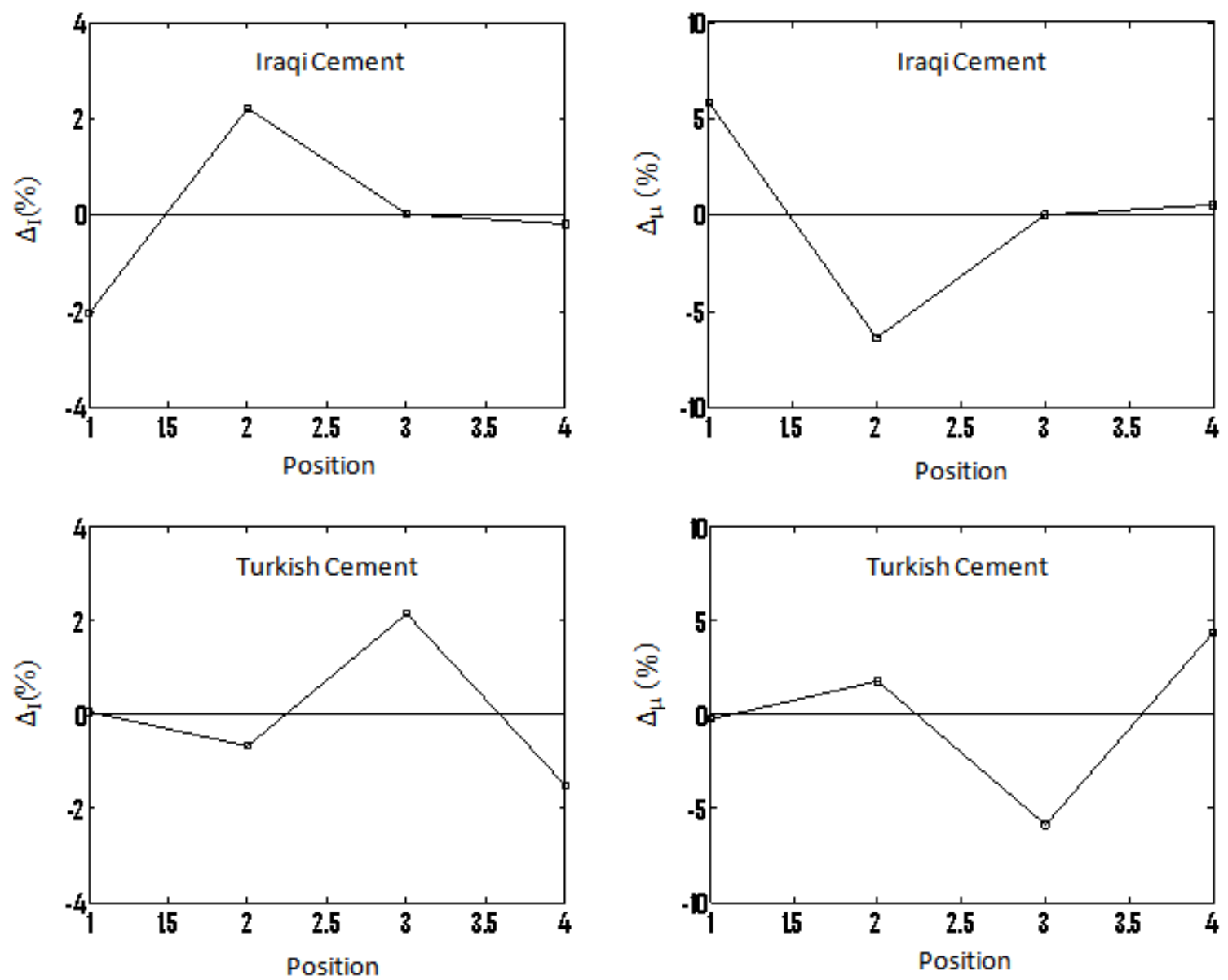

Figure 4. The relationship between each $\Delta_{\mathrm{I}}(\%)$ and $\Delta_{\mu}(\%)$ with the position for Cement material
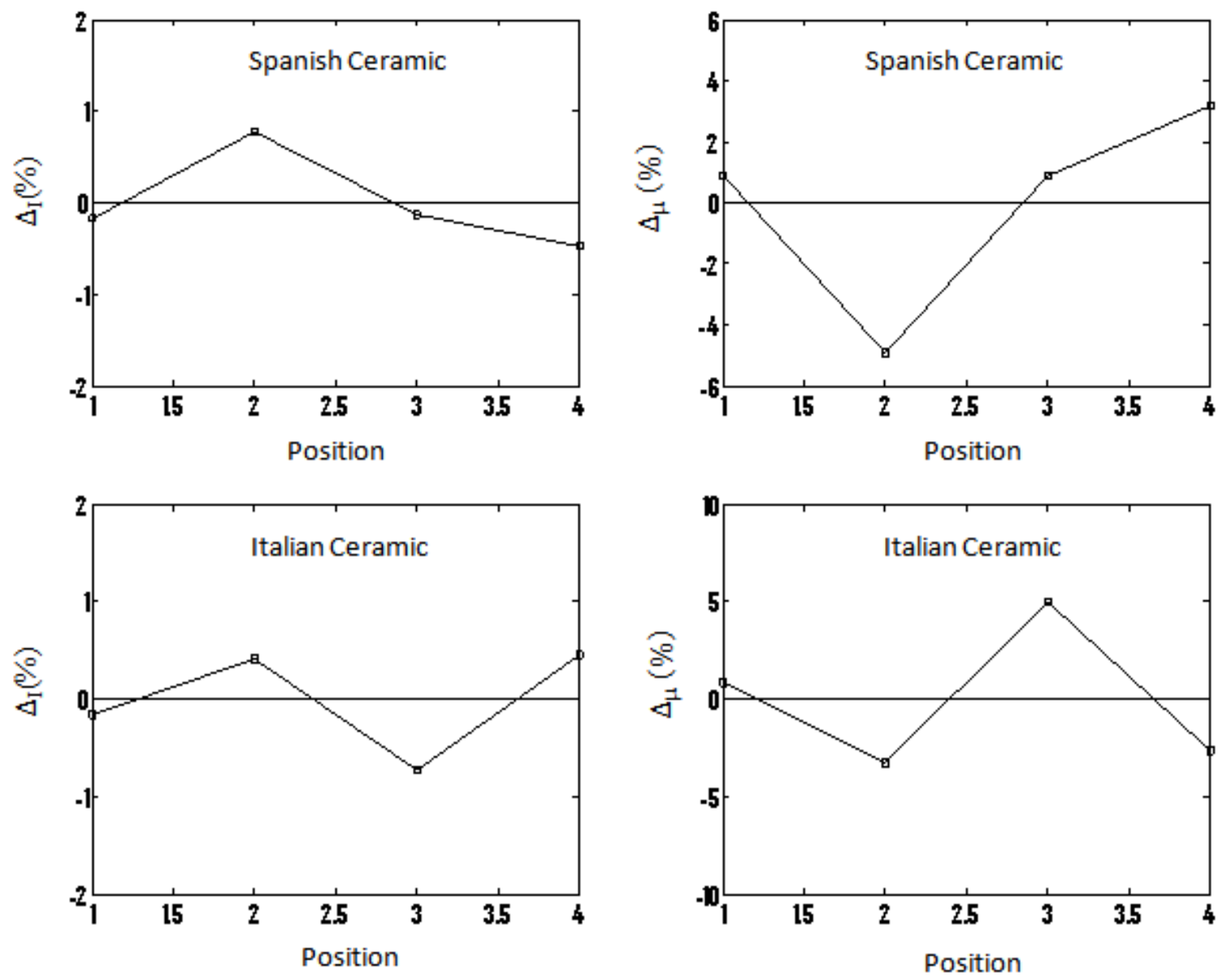

Figure 5. The relationship between each $\Delta_{\mathrm{I}}(\%)$ and $\Delta_{\mu}(\%)$ with the position for Ceramic material 

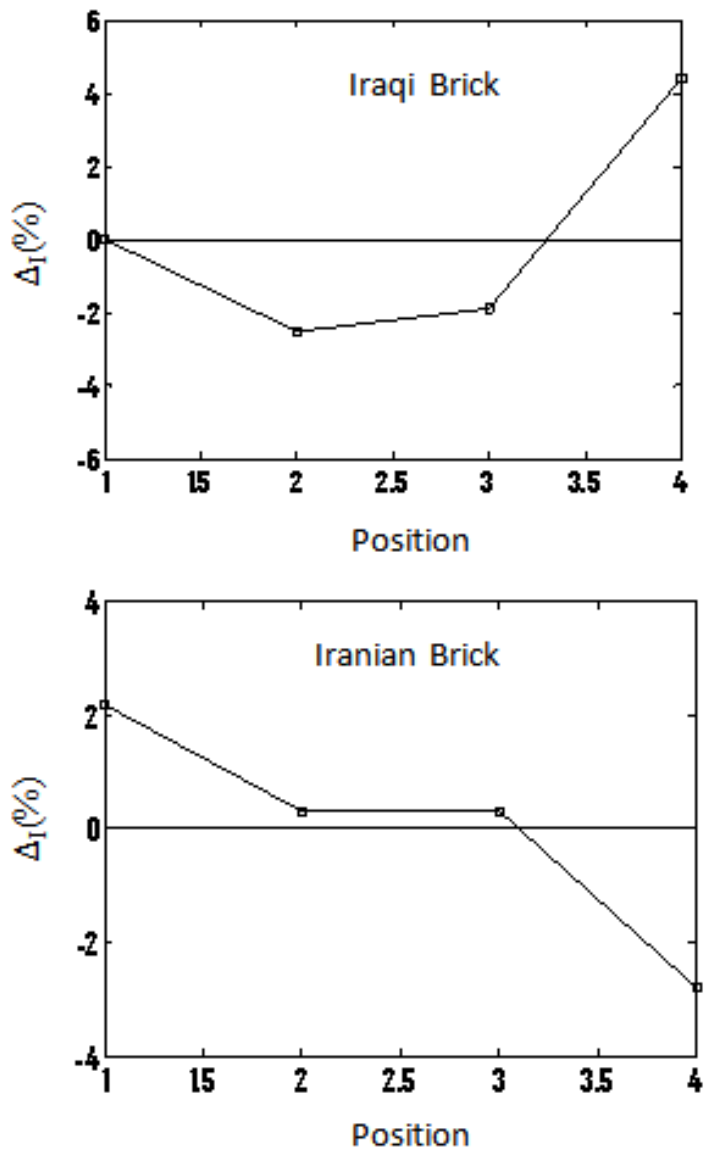
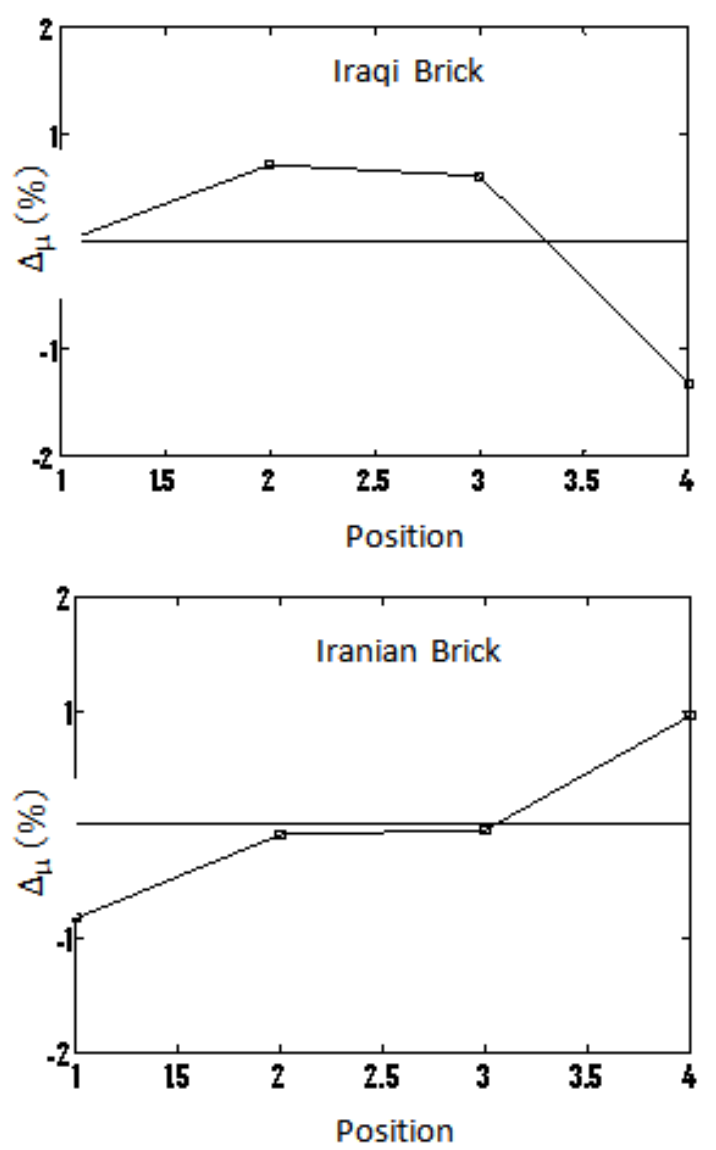

Figure 6. The relationship between each $\Delta_{\mathrm{I}}(\%)$ and $\Delta_{\mu}(\%)$ with the position for Brick material

The average values of linear attenuation Coefficient of gamma rays varies from $0.218 \mathrm{~cm}^{-1}$ (Spanish Granite) to $0.159 \mathrm{~cm}^{-1}$ (Iraqi Brick). The average values of linear attenuation Coefficient were $0.206 \mathrm{~cm}^{-1}, 0.194 \mathrm{~cm}^{-1}, 0.192$ $\mathrm{cm}^{-1}, 0.171 \mathrm{~cm}^{-1}$ and $0.16 \mathrm{~cm}^{-1}$ for building materials, Granite, Marble, Cement, Ceramic and Bricks, respectively. Current results have shown that Granite is one of the best building materials to be used in shielding against gamma rays, whereas Bricks showed less ability to attenuate gamma rays, because Bricks density is low as compared with the Granite density. The current values of $\mu$ for Granite material ranged from $0.198 \mathrm{~cm}^{-1}$ to 0.218 $\mathrm{cm}^{-1}$ are comparable with those reported by Mavi [7] and higher than the value of $\mu$ of known shielding materials, for example Concrete (white sand) [8], Diorite rock [9] and compressed soil [10].

\section{Conclusions}

The building materials used in our markets are different in their homogeneity, so we used a narrow collimated beam of mono- energetic gamma rays to test the homogeneity of materials. The transmitted intensity of gamma-rays at different positions for each sample $\Delta_{\mathrm{I}}(\%)$, linear attenuation coefficient $\Delta_{\mu}(\%)$ and the percentage of standard deviation $((\sigma /$ Ave $) \times 100)$ were used in the examination of the homogeneity of materials. It was observed from the values of $\Delta_{\mathrm{I}}(\%), \Delta_{\mu}(\%)$ and $((\sigma /$ Ave $)$ $\times 100$ ) shown in Table 1 to Table 5 and Figure 2 to Figure 6 that the Spanish Ceramic sample is more homogeneous while the Chinese Granite sample is less homogeneous as compared with the other building materials. Current results have shown that Granite is one of the best building materials to be used in shielding against gamma rays.

\section{References}

[1] Lilley J (2001) Nuclear physics principles and application. Wiley, University of Manchester, New York.

[2] Suleiman WA, Ali S A (2005) Using beta-particle for measuring the homogeneity of rubber compound and studying the effect of compression, temperature and pressure on its homogeneity and mechanical properties. Raf J Sci 16(1):115-121.

[3] Ali S A, Suleiman W A (2006) The effect of mixing time on the homogeneity and mechanical specifications for rubber mixtures. Raf J Sci 17(1): 103-110.

[4] Moreir A C, Appoloni C R, Oliveira M V, Fernandes C P (2007) Structural Characterization of Titanium Porous Foams by Gamma Ray Transmission and X-Rays Microtomography, International Nuclear Atlantic Conference, INAC Sontos, SP, Brazel September 30 to October 5 .

[5] Mheemeed A K, Hasan I H, Al-Jomaily F M(2012) Gamma-ray absorption using rubber-lead mixtures as radiation protection shields. J Radioanal Nucl Chem 291:653-659.

[6] Eaves G (1964) Principles of radiation protection, Iliffe Books Ltd, London.

[7] Mavi B (2012) Experimental investigation of $\gamma$-ray attenuation coefficients for granites. Annals of Nuclear Energy 44:22-25.

[8] Jameel H, Al-dayel O, Al-horayess O, Al-ajyan T (2010) Gamma ray shielding from white sand. Energy Power Eng 2(1): 6-9.

[9] El-Taher A (2007) Comparative study of attenuation and scattering of gamma-rays through two intermediate rocks. Indian J Pure Appl Phys 45:198-203.

[10] Murbut A, Namah A, Taki A (2000) Measurement of gamma-ray attenuation in compressed soil sample. Sci J Iraqi At Energy Comm 2(2):46-52. 